\title{
Empirical Model for Estimating Global Solar Radiation on Horizontal Surfaces for Selected Cities in the Six Geopolitical Zones in Nigeria
}

\author{
M. S. Okundamiya ${ }^{1}$ and A. N. Nzeako ${ }^{2}$ \\ ${ }^{1}$ Department of Electrical and Electronic Engineering, Ambrose Alli University, P.M.B. 14, Ekpoma 234, Nigeria \\ ${ }^{2}$ Department of Electronic Engineering, University of Nigeria, Nsukka 234, Nigeria
}

Correspondence should be addressed to M. S. Okundamiya, st_mico@yahoo.com

Received 2 October 2010; Revised 3 December 2010; Accepted 19 February 2011

Academic Editor: Onur Toker

Copyright () 2011 M. S. Okundamiya and A. N. Nzeako. This is an open access article distributed under the Creative Commons Attribution License, which permits unrestricted use, distribution, and reproduction in any medium, provided the original work is properly cited.

\begin{abstract}
This study proposes a temperature-based model of monthly mean daily global solar radiation on horizontal surfaces for selected cities, representing the six geopolitical zones in Nigeria. The modelling was based on linear regression theory and was computed using monthly mean daily data set for minimum and maximum ambient temperatures. The results of three statistical indicators: Mean Bias Error (MBE), Root Mean Square Error (RMSE), and $t$-statistic (TS), performed on the model along with practical comparison of the estimated and observed data, validate the excellent performance accuracy of the proposed model.
\end{abstract}

\section{Introduction}

Global solar radiation is an important parameter necessary for most ecological models and serves as input for different photovoltaic conversion system; hence, it is of economic importance to renewable energy alternative. The solar radiation reaching the earth's surface depends on the climatic condition of the specific site location, and this is essential for accurate prediction and design of a solar energy system [1].

When global solar radiation is used to generate electrical energy for any specific site location, a provision should be made to forecast solar energy which will convert to electrical energy to recover the load demand, that is, the amount of solar energy for that place ought to be known. Technology for measuring global solar radiation is costly and has instrumental hazards [2]. Although solar radiation data are available in most meteorological stations, many stations in developing countries (including Nigeria) suffer from a shortage concern of these data. Thus, alternative methods for estimating these data are required [3]. One of these methods is the use of empirical models. Accurate modelling depends on the quality and quantity of the measured data used and is a good tool for generating global solar radiation at locations where measured data are not available.

Several models have been proposed to estimate global solar radiation. Page [4] presents a linear regression model used in correlating the global solar radiation data with relative sunshine duration, which is a modified Angstromtype model [5]. Badescu [6] studied existing relationships between monthly mean clearness index and the number of bright sunshine hours using the data obtained from Romania, Trabea, and Shaltout [7] studied the correlation between the measurements of global solar radiation and the meteorological parameters using solar radiation, mean daily maximum temperature, mean daily relative humidity, mean daily sea level pressure, mean daily vapour pressure, and hours of bright sunshine data obtained from different parts of Egypt; while Sfetsos and Coon $\imath$ ck [8] used artificial intelligence techniques to forecast hourly global solar radiation. Okogbue and Adedokun [9] estimated the global solar radiation at Ondo, Nigeria, while Ulgen and Hepbasli [10] correlated the ratio of monthly average hourly diffuse solar radiation to monthly average hourly global solar radiation with the monthly average hourly clearness 
index in form of polynomial relationships for the city of Izmir, Turkey. In another study, Ulgen and Hepbasli [11] correlated solar radiation parameters (global and diffuse solar radiation) with respect to ambient temperature in the fifth order. Several investigations [12-14] have demonstrated the predictive ability of the Angstrom-type model, correlating the global solar radiation to relative sunshine duration in a simple linear regression form. Menges et al. [15] reviewed and tested available global solar radiation models to compute the monthly average daily global solar radiation on a horizontal surface using the data obtained from Konya, Turkey. Kaplanis [16] described computationally efficient and intuitively simple model to estimate hourly global solar radiation on a horizontal surface. Falayi et al. [17] based their studies on the correlation between global solar radiation and meteorological parameters using monthly average daily global solar radiations, sunshine duration, temperature, and relative humidity data obtained from Iseyin, Nigeria.

In this study, a solar resource parameter (ambient temperature) has been analyzed to deduce a two-parameter temperature-based linear model for estimating the global solar radiation on horizontal surfaces at different cities in the six geopolitical zones in Nigeria using monthly mean daily minimum and maximum temperatures for Abuja, Benin City, Katsina, Lagos, Nsukka, and Yola.

\section{Materials and Methods}

The monthly mean daily global solar radiation on horizontal surfaces and monthly mean daily ambient temperatures (minimum and maximum) were obtained from the archives of National Aeronautics and Space Administration (NASA) [18] for a ten-year period (1996-2005) for six cities: Abuja, Benin City, Katsina, Lagos, Nsukka, and Yola, located, respectively, in the North-Central, South-South, NorthWestern, South-Western, South-Eastern, and North-Eastern Nigeria as shown in Figure 1.

2.1. Data Analysis. Stochastic analysis was employed on these data to deduce a set of linear models using a sevenyear period (1996-2002) monthly mean daily data set while a three-year period (2003-2005) monthly mean daily data set was used to validate the proposed model. The performance of the proposed model was evaluated using the $t$-statistic (TS), a statistical indicator proposed by Stone [19], Root Mean Square Error (RMSE), and Mean Bias Error (MBE). These indicators are mainly employed for adjustment of solar radiation data $[3,17,20]$.

The TS was chosen as it allows models to be compared and, at the same time, can induce whether or not a model's estimate is statistically significant at a particular confidence level (in this study, the performance was analyzed based on the $95 \%$ confidence level). It takes into account the dispersion of the results, and it can be computed in terms of RMSE and MBE as shown in the appendix.

2.2. Process Simulation. Computer codes were developed in MATLAB for simulating and evaluating the performance of the developed model while stochastic analysis was performed using Microsoft Excel 2007. Table 1 shows the summary of the stochastic analysis performed on clearance index, ambient temperature ratio, and maximum ambient temperature along with the statistical comparison between the observed and estimated values of the monthly mean daily global solar radiation on horizontal surfaces for the study locations.

\section{Results}

The results of the analysis suggest that a significant statistical relationship (with coefficient of correlation (CC) of 89.997.6\%) exists between the clearance index, ambient temperature ratio, and maximum ambient temperature with linear regression model

$$
\bar{H}=\bar{H}_{\mathrm{o}}\left(m_{0}+m_{1} \bar{R}_{T}+m_{2} \bar{T}_{\max }\right),
$$

and the ambient temperature ratio is given by

$$
\bar{R}_{T}=\frac{\bar{T}_{\min }}{\bar{T}_{\max }},
$$

where $\bar{H}, \bar{H}_{\mathrm{o}}, \bar{R}_{T}, \bar{T}_{\min }$, and $\bar{T}_{\text {max }}$ are the respective monthly mean daily horizontal global- and extraterrestrial-radiation, minimum to maximum ambient temperature ratio, and minimum- and maximum-ambient temperature, while $m_{0}$, $m_{1}$, and $m_{2}$ are empirical constants. Detailed analysis of $\bar{H}_{o}$, is given in the appendix. The result of the analysis on (1) is presented in Table 1.

Based on the results in Table 1, an empirical model has been proposed for estimating the monthly mean daily global solar radiation on a horizontal surface using minimum and maximum ambient temperature meteorological data. From Table 1, the empirical model investigated in this study is stated as follows.

$$
\begin{aligned}
& \text { Model for Abuja: } \\
& \bar{H}_{\mathrm{Abj}}=\bar{H}_{o}\left(-1.2560+0.3815 \bar{R}_{T}+0.05440 \bar{T}_{\max }\right) . \\
& \text { Model for Benin City: } \\
& \bar{H}_{\mathrm{Ben}}=\bar{H}_{o}\left(0.2284-1.0960 \bar{R}_{T}+0.03981 \bar{T}_{\max }\right) .
\end{aligned}
$$

Model for Katsina:

$\bar{H}_{\text {Kat }}=\bar{H}_{o}\left(0.5033-0.2487 \bar{R}_{T}+0.00932 \bar{T}_{\text {max }}\right)$.

Model for Lagos:

$$
\begin{aligned}
& \bar{H}_{\mathrm{Lag}}=\bar{H}_{o}\left(2.6500-3.0010 \bar{R}_{T}+0.01945 \bar{T}_{\max }\right) . \\
& \text { Model for Nsukka: } \\
& \bar{H}_{\mathrm{Nsu}}=\bar{H}_{o}\left(0.2445-0.8525 \bar{R}_{T}+0.03240 \bar{T}_{\max }\right) .
\end{aligned}
$$

Model for Yola:

$\bar{H}_{\text {Yol }}=\bar{H}_{o}\left(0.6187-0.4966 \bar{R}_{T}+0.01031 \bar{T}_{\max }\right)$. 


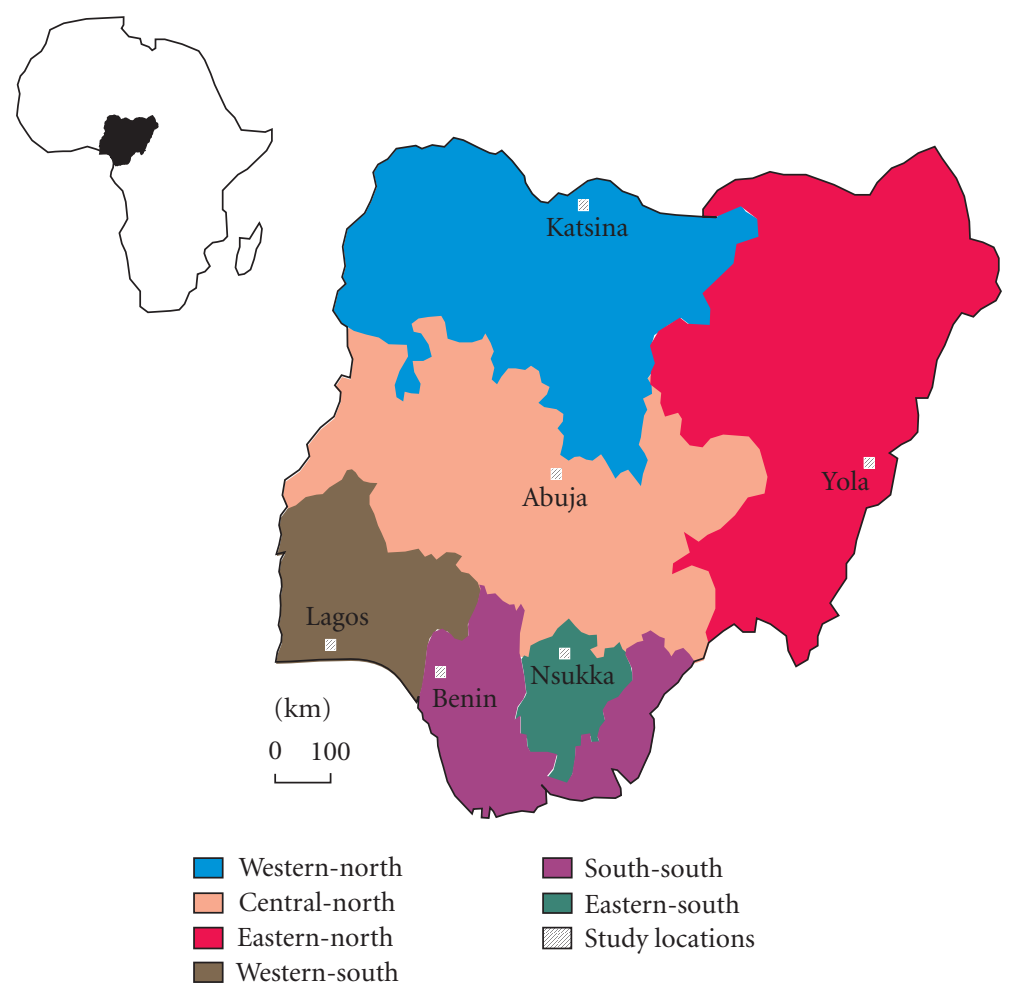

Figure 1: Site map of study locations.

TABLE 1: Results of stochastic analysis on temperature-based linear regression model of (1) along with the geographical locations for selected cities in Nigeria.

\begin{tabular}{|c|c|c|c|c|c|c|c|c|c|c|}
\hline \multirow{2}{*}{ Cities } & \multirow{2}{*}{ Lat. $\left({ }^{\circ} \mathrm{N}\right)$} & \multirow{2}{*}{ Long. $\left({ }^{\circ} \mathrm{E}\right)$} & \multicolumn{3}{|c|}{ Empirical constants } & \multirow{2}{*}{ CC $(\%)$} & \multirow{2}{*}{$\mathrm{CD}(\%)$} & \multirow{2}{*}{$\mathrm{MBE}$} & \multirow{2}{*}{ RMSE } & \multirow{2}{*}{ TS } \\
\hline & & & $m_{0}$ & $m_{1}$ & $m_{2}$ & & & & & \\
\hline Abuja & 9.08 & 7.53 & -1.2560 & 0.3815 & 0.05440 & 95.7 & 91.6 & -0.0109 & 0.2648 & 0.1370 \\
\hline Benin City & 6.34 & 5.63 & 0.2284 & -1.0960 & 0.03981 & 97.6 & 95.2 & 0.0023 & 0.1632 & 0.0473 \\
\hline Katsina & 13.00 & 7.60 & 0.5033 & -0.2487 & 0.00932 & 89.9 & 80.9 & -0.0024 & 0.2685 & 0.0295 \\
\hline Lagos & 6.45 & 3.40 & 2.6500 & -3.0010 & 0.01945 & 94.6 & 89.5 & -0.0364 & 0.2216 & 0.5527 \\
\hline Nsukka & 6.86 & 7.39 & 0.2445 & -0.8525 & 0.03240 & 94.9 & 90.1 & -0.0047 & 0.2016 & 0.0780 \\
\hline Yola & 10.38 & 12.87 & 0.6187 & -0.4966 & 0.01031 & 93.5 & 87.5 & 0.0429 & 0.1900 & 0.7683 \\
\hline
\end{tabular}

Figure 2 shows the correlation between the estimated and observed values of the monthly mean global solar radiation while Figure 3 shows a comparison of the estimated values of the monthly mean daily global solar radiation obtained using (3)-(8) and their corresponding observed values.

\section{Discussion}

The following observations can be made from a study of the results presented in Table 1. The RMSE values, which are a measure of the accuracy of estimation, vary from 0.1632 to 0.2685 (lowest for (4) while (5) gives the highest value). The MBE values obtained are positive for (4) and (8) and negative for (3), (5), (6), and (7). This shows that the models vary between over and under estimation of $\bar{H}$. However, the value of MBE from the model for Lagos (see (6)) has the highest underestimation while model for Yola has the highest overestimation. The model for Benin City (see (4)) has negligible overestimation. The high values of the coefficient of determination (CD) of the proposed models (0.8090.952 ) shows good agreement of estimated to observed values of $\bar{H}$ (Figure 3 ).

The use of an additional tool, TS, is used to achieve a more reliable statistical result. This is because it is possible to have large RMSE values and at the same time a very small MBE (Table 1). The smaller the value of $t$, the better the model's performance is. To determine whether a model's estimates are statistically significant, we determined the critical $t$-value from standard statistical tables at $(P-1)$ degrees of freedom, that is, $t_{c(\alpha / 2)}$ at the $\alpha$ level of significance. For the model's estimates to be judged statistically significant at the $(1-\alpha)$ confidence level, the calculated $t$-value must 


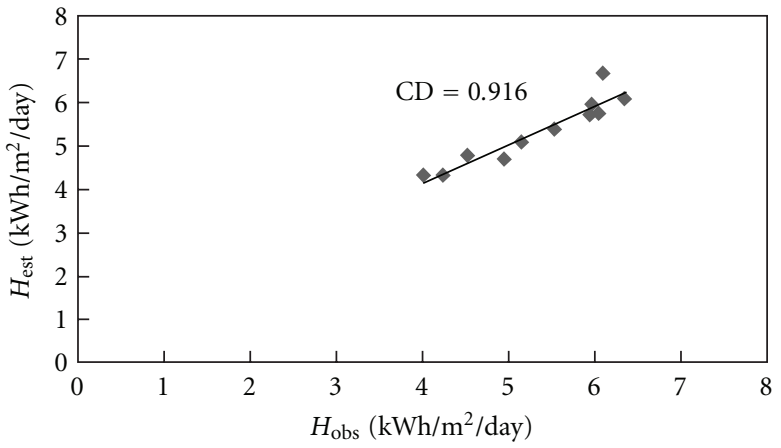

(a)

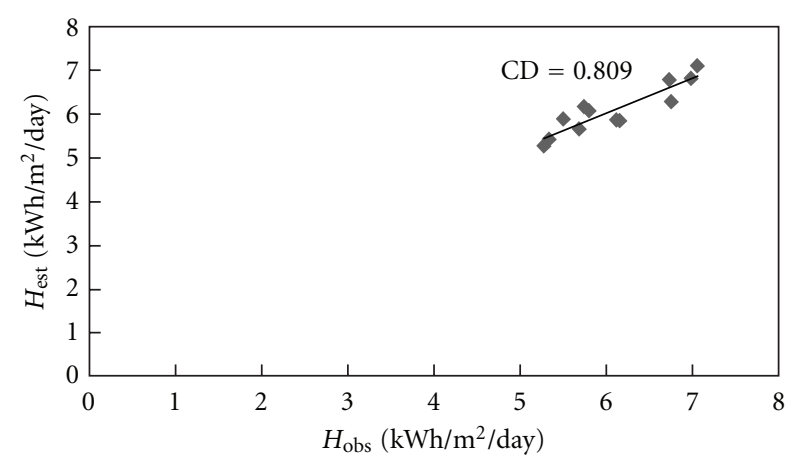

(c)

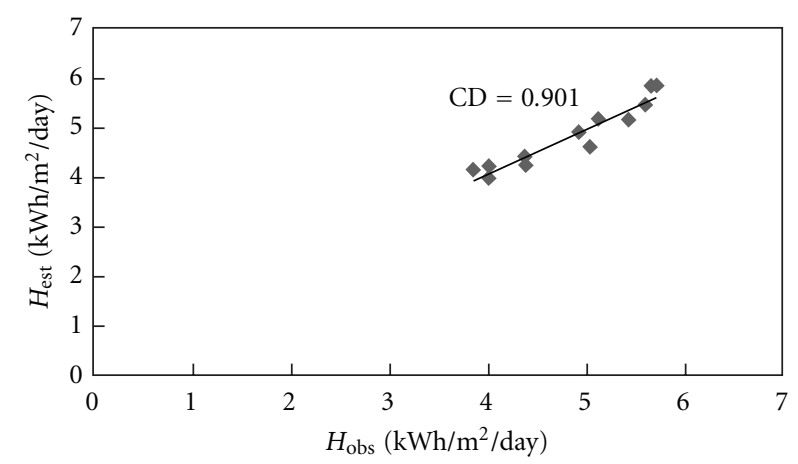

(e)

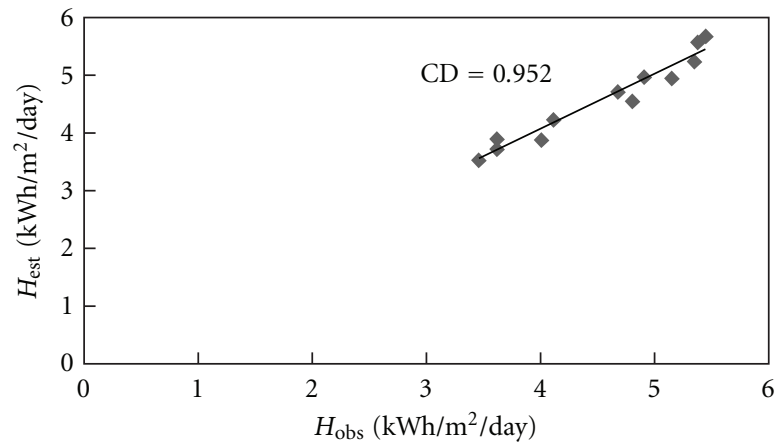

(b)

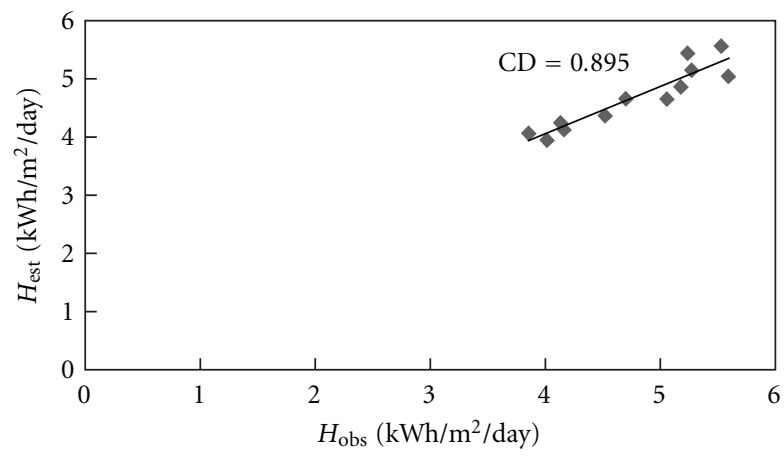

(d)

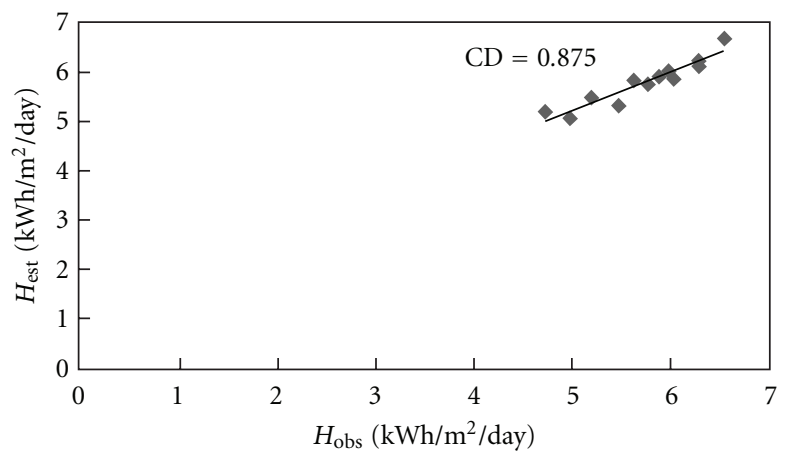

(f)

Figure 2: Correlation between the estimated and observed values of the monthly mean daily global solar radiation. (a) Abuja, (b) Benin City, (c) Katsina, (d) Lagos, (e) Nsukka, and (f) Yola.

be between the interval defined by $-t_{c}$ and $t_{c}$ (acceptance region under the reduced normal distribution curve), that is, $t$-values outside the range of critical $t$-values show that the equation has no statistical significance. The $t$-value of the proposed models are within the range of critical $t$ value, $\left(t_{c(0.025)}=1.96\right)$. However, a low $t$-value of the proposed model (0.0295-0.7683) demonstrates the excellent performance of the proposed models.

The results on Figure 3 and Table 1 validate the performance of the proposed models for estimating the monthly mean daily global solar radiation on a horizontal surface for different cities in Nigeria. However, to further improve the accuracy (coefficient of determination) of the estimated results additional meteorological parameters should be included in the model. In this study, other parameters are not considered as it is intended to establish simple and accurate means of estimating monthly mean daily global solar radiation data on horizontal surfaces.

As noticed from Figure 3, the cities under study experienced a decrease in the horizontal global solar radiation from March through August (during rainy season) with Benin City having the lowest monthly mean daily horizontal global solar radiation of $3.46 \mathrm{kWh} / \mathrm{m}^{2} /$ day in July. During the commencement of dry season (September to November) when other cities experienced a rapid increase in their solar radiation, only Katsina maintained a gradual decrease in her global radiation (having her least radiation of $5.37 \mathrm{kWh} / \mathrm{m}^{2} /$ day in December). Thus, the variation of daily horizontal global solar radiation with month of the year in Katsina differs from others (with identical variation). This is as a result of her geographical location (long. $7.60^{\circ} \mathrm{E}$, lat. $\left.13.00^{\circ} \mathrm{N}\right)$. 


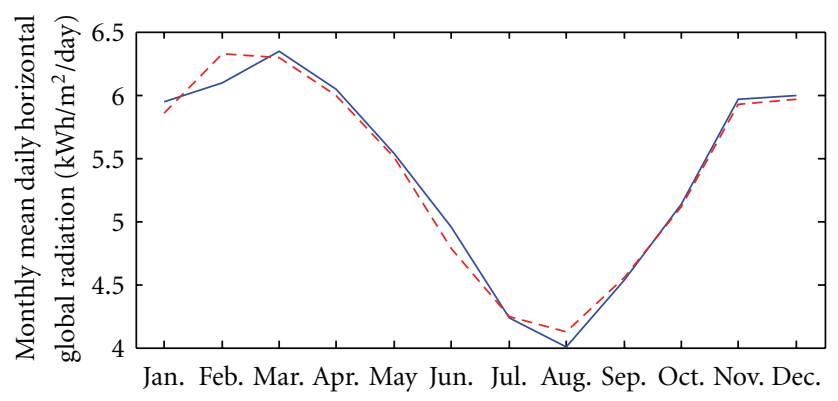

(a)

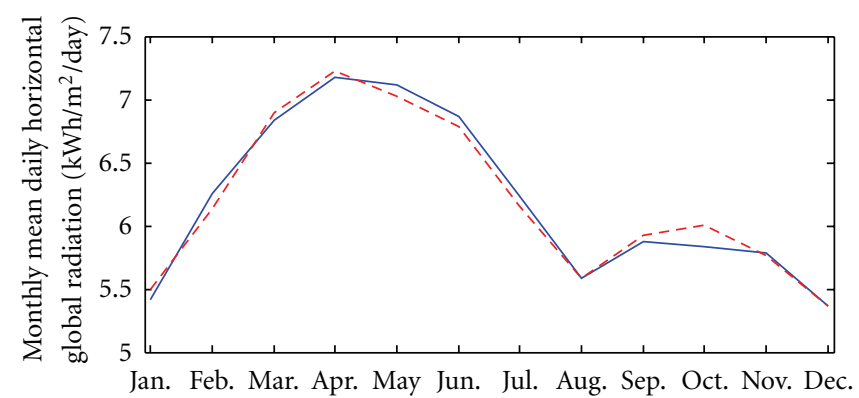

(c)

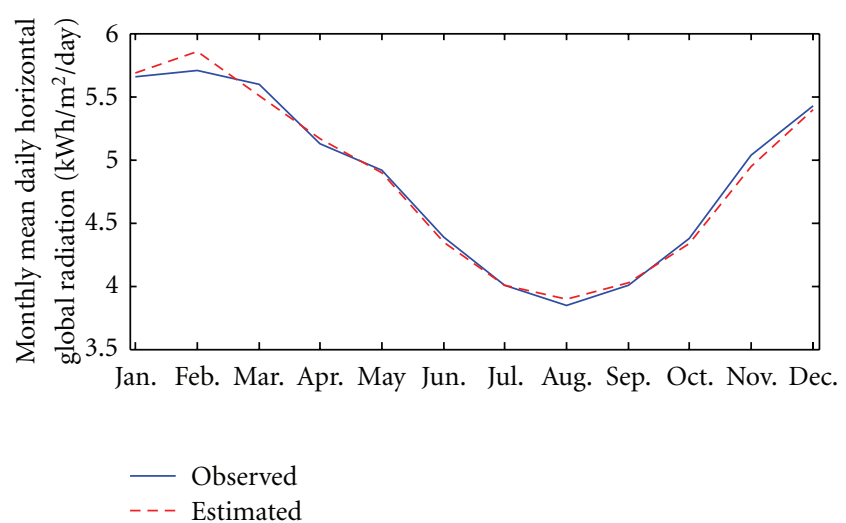

(e)

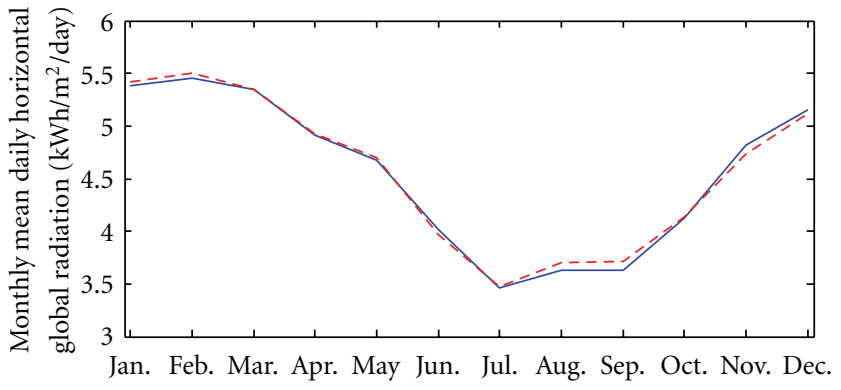

(b)

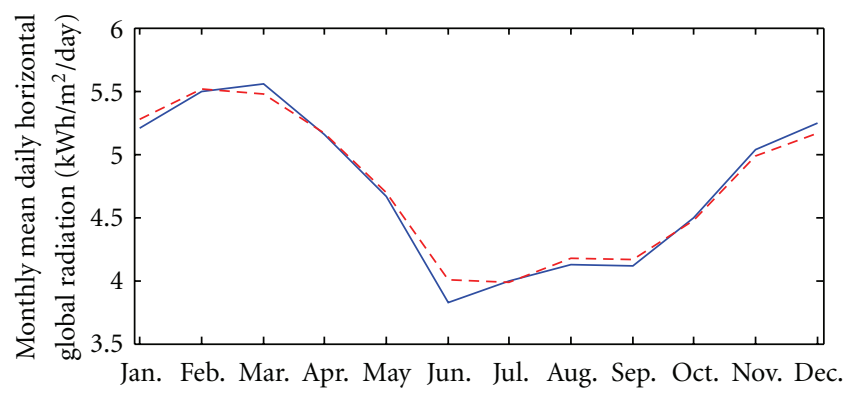

(d)

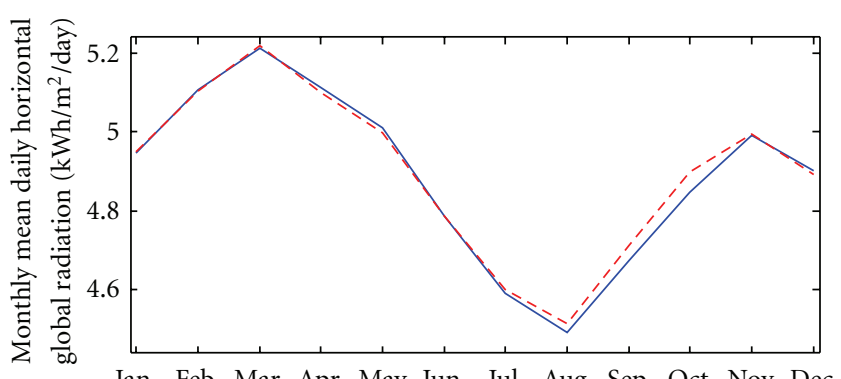

Jan. Feb. Mar. Apr. May Jun. Jul. Aug. Sep. Oct. Nov. Dec.

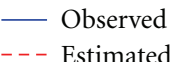

(f)

FIGURE 3: Comparison of the estimated and observed monthly mean horizontal global solar radiation data: (a) Abuja, (b) Benin City, (c) Katsina, (d) Lagos, (e) Nsukka, and (f) Yola.

\section{Conclusion}

Climatological data have been employed in this study to develop a temperature-based empirical model. The results of this research clearly indicate the main significance of developing empirical models for estimating the global solar radiation on horizontal surfaces reaching the earth at different geopolitical zones in Nigeria. The developed model can also be applied to other cities not considered (in the six geopolitical zones in Nigeria), with the determination of new empirical constants. The low MBE value, which (0.00230.0429) exhibited by the proposed models imply they have good long-term representation of the physical problem. The RMSE values lie in the range 0.1632 to 0.2685 indicate good agreement between the estimated and observed $\bar{H}$.
The global solar radiation intensity produced by the proposed model can be utilized in design, analysis, and performance estimation of solar energy conversion system, which is gaining significant attention in Nigeria in particular and the world at large.

\section{Appendix}

In this section, an overview of the basic solar system parameters and their computation is presented.

(1) Solar constant $\left(I_{\mathrm{SC}}\right)$ : it is the energy from the sun per unit time received on a unit area of surface perpendicular to the direction of propagation of radiation at the mean earth-sun distance outside the atmosphere, which is numerically equal to $1.367 \mathrm{~kW} / \mathrm{m}^{2}$ [21]. 
(2) Solar time $\left(t_{s}\right)$ : it is the time that is based on apparent angular motion of the sun across the sky. The time where the sun crosses the meridian of the observer is called solar noon. At solar noon, $t_{s}=12 \mathrm{~h}$. It is given by

$$
t_{s}=t_{c}+E+\frac{\vartheta}{15^{\circ}}-Z_{e}
$$

where $t_{c}$ is the civil time in hours corresponding to the midpoint of each time step, $\vartheta$ is the longitude in degrees of the site location, $Z_{e}$ is the time zone in hours to the east of GMT (which is $+1 \mathrm{~h}$ for Nigeria), and $E$ is the equation of time in hours. The equation of time is given as

$$
\begin{aligned}
& E= 3.82(0.000075+0.001868 \cos B-0.032077 \sin B \\
&-0.014615 \cos 2 B-0.04089 \sin 2 B), \\
& B=(d-1) \frac{360^{\circ}}{365}
\end{aligned}
$$

where $d=$ Day of the year, starting with 1 for January 1st, that is, $1 \leq d \leq 365$.

(3) Declination angle $(\delta)$ : it is the angle made by the line joining the centre of the sun and the earth with its projection on the equatorial plane. It is zero at the autumnal and vernal equinoxes, $23.45^{\circ}$ at the summer solstice on June 21 , and $-23.45^{\circ}$ at the winter solstice on December 21 in the northern hemisphere. Thus, it has a range $-23.45^{\circ} \leq \delta \leq$ $23.45^{\circ}$. According to Cooper [22] at the intervening periods of the year, solar declination angle can be approximated by a sinusoidal variation as

$$
\delta=23.45^{\circ} \sin \left(360^{\circ} \frac{284+d}{365}\right) .
$$

(4) Hour angle $(\omega)$ : it is the angular displacement of the sun East or West of the local meridian due to the rotation of the earth on its axis at $15^{\circ}$ per hour, which expresses the time of the day with respect to solar noon as

$$
\omega=\left(t_{S}-12\right) 15^{\circ},
$$

while the sunset hour angle is defined as

$$
\omega_{s}=\cos ^{-1}[-\tan \delta \tan \phi],
$$

where $\omega=$ hour angle $\left({ }^{\circ}\right)$ and $\omega_{s}=$ sunset hour angle $\left({ }^{\circ}\right)$.

(5) Extraterrestrial radiation on a horizontal surface: it is the theoretical possible radiation that would be available if there were no atmosphere. At any point in time (between sunrise and sunset), the extraterrestrial horizontal radiation is

$I_{0}=I_{\mathrm{SC}}\left(1+0.033 \cos \frac{360 d}{365}\right)[\sin \delta \sin \phi+\cos \delta \cos \phi \cos \omega]$.
The total daily extraterrestrial radiation on a horizontal surface is obtained by integrating (A.6) over the period from sunrise to sunset; thus,

$$
\begin{aligned}
H_{0}= & \frac{24}{\pi} I_{\mathrm{SC}}\left(1+0.033 \cos \frac{360 d}{365}\right) \\
& \times\left[\frac{\pi \omega_{s}}{180} \sin \delta \sin \phi+\cos \delta \cos \phi\right]
\end{aligned}
$$

and the monthly mean daily extraterrestrial radiation on a horizontal surface is

$$
\bar{H}_{0}=\frac{1}{D} \sum_{d_{m}=1}^{D} H_{0}\left(d_{m}\right)
$$

where $d_{m}$ is the day of the month and $D$ is the total number of days in the month.

The ratio of monthly mean daily global radiation on horizontal surface to monthly mean daily extraterrestrial horizontal radiation is called the clearance index given as

$$
K_{T}=\frac{\bar{H}}{\bar{H}_{0}}
$$

Mean Bias Error (MBE) is defined as

$$
\mathrm{MBE}=\frac{1}{P} \sum_{p=1}^{P}\left(\bar{H}_{\mathrm{est}}-\bar{H}_{\mathrm{obs}}\right) .
$$

Root Mean square Error (RMSE) is defined as

$$
\mathrm{RMSE}=\sqrt{\frac{1}{P}\left[\sum_{p=1}^{P}\left(\bar{H}_{\mathrm{est}}-\bar{H}_{\mathrm{obs}}\right)^{2}\right]} .
$$

And $t$-Statistic (TS) is defined as

$$
\mathrm{TS}=\sqrt{\left[\frac{(P-1)(\mathrm{MBE})^{2}}{\left(\mathrm{RMSE}^{2}-\mathrm{MBE}^{2}\right)}\right]},
$$

where $\bar{H}_{\text {obs }}$ is the observed $\bar{H}\left(\mathrm{kWh} / \mathrm{m}^{2} /\right.$ day $), \bar{H}_{\text {est }}$ is the estimated $\bar{H}\left(\mathrm{kWh} / \mathrm{m}^{2} /\right.$ day $)$, and $P$ is the numbers of observations and $p$ corresponds to the twelve months $(P=12)$ of the year in this study. 


\section{Nomenclature}

$I_{\mathrm{SC}}: \quad$ Solar constant $\left(\mathrm{kW} / \mathrm{m}^{2}\right)$

$I_{o}$ : $\quad$ Hourly extraterrestrial radiation on a horizontal surface $\left(\mathrm{kw} / \mathrm{m}^{2}\right)$

$\bar{H}: \quad$ Monthly mean daily global radiation on a horizontal surface $\left(\mathrm{kWh} / \mathrm{m}^{2} /\right.$ day $)$

$\bar{H}_{o}$ : Monthly mean daily extraterrestrial radiation on a horizontal surface $\left(\mathrm{kWh} / \mathrm{m}^{2} /\right.$ day $)$

$H_{o}$ : Daily extraterrestrial radiation on a horizontal surface $\left(\mathrm{kWh} / \mathrm{m}^{2} /\right.$ day $)$

$\bar{T}_{\max }:$ Monthly mean daily maximum ambient temperature $\left({ }^{\circ} \mathrm{C}\right)$

$\bar{T}_{\text {min }}: \quad$ Monthly mean daily minimum ambient temperature $\left({ }^{\circ} \mathrm{C}\right)$

$\bar{R}_{T}$ : $\quad$ Monthly mean daily ambient temperature ratio

$K_{T}: \quad$ Clearance index

$t_{s}: \quad$ Solar time $(\mathrm{h})$

$t_{c}: \quad$ Civil time (h)

$E: \quad$ Equation of time (h)

$Z_{e}: \quad$ Time zone to the east of GMT (h)

$\delta: \quad$ Declination angle $\left({ }^{\circ}\right)$

$\omega: \quad$ Hour angle $\left({ }^{\circ}\right)$

$\omega_{s}: \quad$ Sunset hour angle $\left({ }^{\circ}\right)$

$\phi: \quad$ Latitude $\left({ }^{\circ}\right)$

9: $\quad$ Longitude $\left({ }^{\circ}\right)$

$d: \quad$ Day of the month

$D: \quad$ Total number of days in the month

$\alpha: \quad$ Level of significance

MBE: Mean Bias Error

RMSE: Root Mean square Error

TS: $\quad t$-statistic

CC: $\quad$ Coefficient of correlation (\%)

CD: Coefficient of determination (\%)

$p$ : $\quad$ Numbers of observations

$P: \quad$ Total numbers of observations.

\section{References}

[1] F. W. Burari and A. S. Sambo, "Model for the prediction of global solar radiation for Bauchi using Meteorological Data," Nigeria Journal of Renewable Energy, vol. 91, pp. 30-33, 2001.

[2] M. S. Alam, S. K. Saha, M. A. K. Chowdhury, M. Saifuzzaman, and M. Rahman, "Simulation of solar radiation system," American Journal of Applied Sciences, vol. 2, no. 4, pp. 751-758, 2005.

[3] A. M. Al-Salihi, M. M. Kadum, and A. J. Mohammed, "Estimation of global solar radiation on horizontal surface using meteorological measurement for different cities in Iraq," Asian Journal of Scientific Research, vol. 3, no. 4, pp. 240-248, 2010.

[4] J. K. Page, "The estimation of monthly mean values of daily total short-wave radiation on vertical and inclined surfaces from sunshine records for latitude $40^{\circ} \mathrm{N}-40^{\circ} \mathrm{S}$," in Proceeding of the UN. Conference on New Sources of Energy, 1964, Paper S/ 98.

[5] A. S. Angstrom, "Solar and terrestrial radiation," Meteorological Society, vol. 50, pp. 121-126, 1924.
[6] V. Badescu, "Correlations to estimate monthly mean daily solar global irradiation: application to Romania," Energy, vol. 24, no. 10, pp. 883-893, 1999.

[7] A. A. Trabea and M. A. M. Shaltout, "Correlation of global solar radiation with meteorological parameters over Egypt," Renewable Energy, vol. 21, no. 2, pp. 297-308, 2000.

[8] A. Sfetsos and A. H. Coonıck, "Unıvariate and multivariate forecasting of hourly solar radiation with artificial intelligence techniques," Solar Energy, vol. 68, pp. 169-178, 2000.

[9] E. C. Okogbue and J. A. Adedokun, "On the estimation of solar radiation at Ondo, Nigeria," Journal of Physics, vol. 14, pp. 9799, 2002.

[10] K. Ulgen and A. Hepbasli, "Prediction of solar radiation parameters through clearness index for Izmir, Turkey," Energy Sources, vol. 24, no. 8, pp. 773-785, 2002.

[11] K. Ulgen and A. Hepbasli, "Estimation of solar radiation parameters for Izmir, Turkey," International Journal of Energy Research, vol. 26, no. 9, pp. 807-823, 2002.

[12] L. E. Akpabio, S. O. Udo, and S. E. Etuk, "Empirical correlations of global solar radiation with meteorological data for Onne, Nigeria," Turkish Journal of Physics, vol. 28, no. 3, pp. 301-307, 2004.

[13] E. O. Falayi and A. B. Rabiu, "Modeling global solar radiation using sunshine duration data," Nigeria Journal of Physics, vol. 17, pp. 181-186, 2005.

[14] B. Safari and J. Gasore, "Estimation of global solar radiation on horizontal surface in Rwanda using empirical model," Asian Journal of Science Research, vol. 2, pp. 68-75, 2009.

[15] H. O. Menges, C. Ertekin, and M. H. Sonmete, "Evaluation of global solar radiation models for Konya, Turkey," Energy Conversion and Management, vol. 47, no. 18-19, pp. 31493173, 2006.

[16] S. N. Kaplanis, "New methodologies to estimate the hourly global solar radiation: comparisons with existing models," Renewable Energy, vol. 31, no. 6, pp. 781-790, 2006.

[17] E. O. Falayi, J. O. Adepitan, and A. B. Rabiu, "Empirical models for the correlation of global solar radiation with meteorological data for Iseyin, Nigeria," International Journal of Physical Sciences, vol. 3, no. 9, pp. 210-216, 2008.

[18] NASA, "Surface Meteorology and Solar Energy Data and Information," 2010, http://eosweb.larc.nasa.gov/sse/.

[19] R. J. Stone, "Improved statistical procedure for the evaluation of solar radiation estimation models," Solar Energy, vol. 51, no. 4, pp. 289-291, 1993.

[20] N. Halouani, C. T. Nguyen, and D. Vo-Ngoc, "Calculation of monthly average global solar radiation on horizontal surfaces using daily hours of bright sunshine," Solar Energy, vol. 50, no. 3, pp. 247-258, 1993.

[21] J. A. Duffie and W. A. Beckman, Solar Engineering of Thermal Processes, John Wiley \& Sons, New York, NY, USA, 3rd edition, 2006.

[22] P. I. Cooper, "The absorption of radiation in solar stills," Solar Energy, vol. 12, no. 3, pp. 333-346, 1969. 

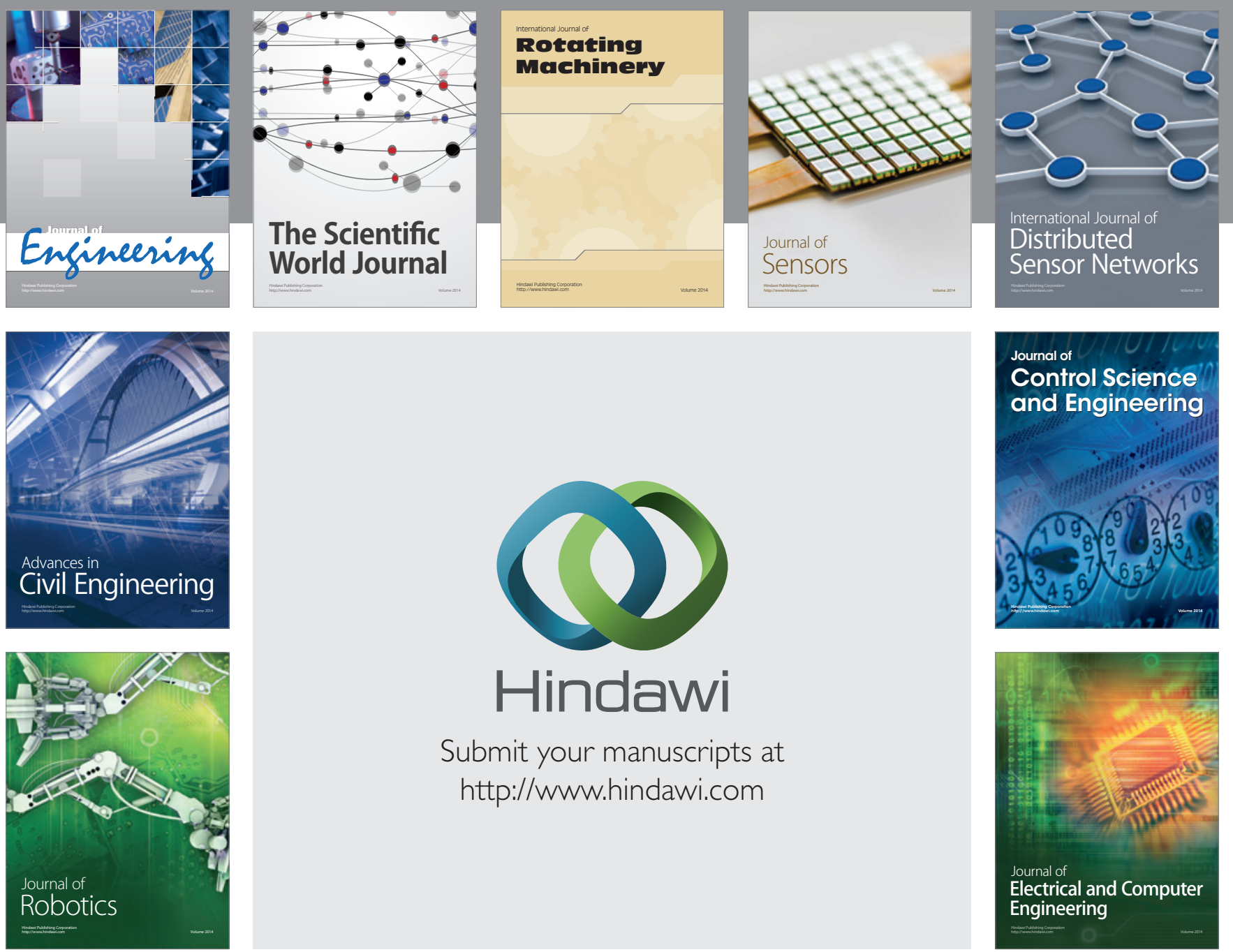

Submit your manuscripts at

http://www.hindawi.com
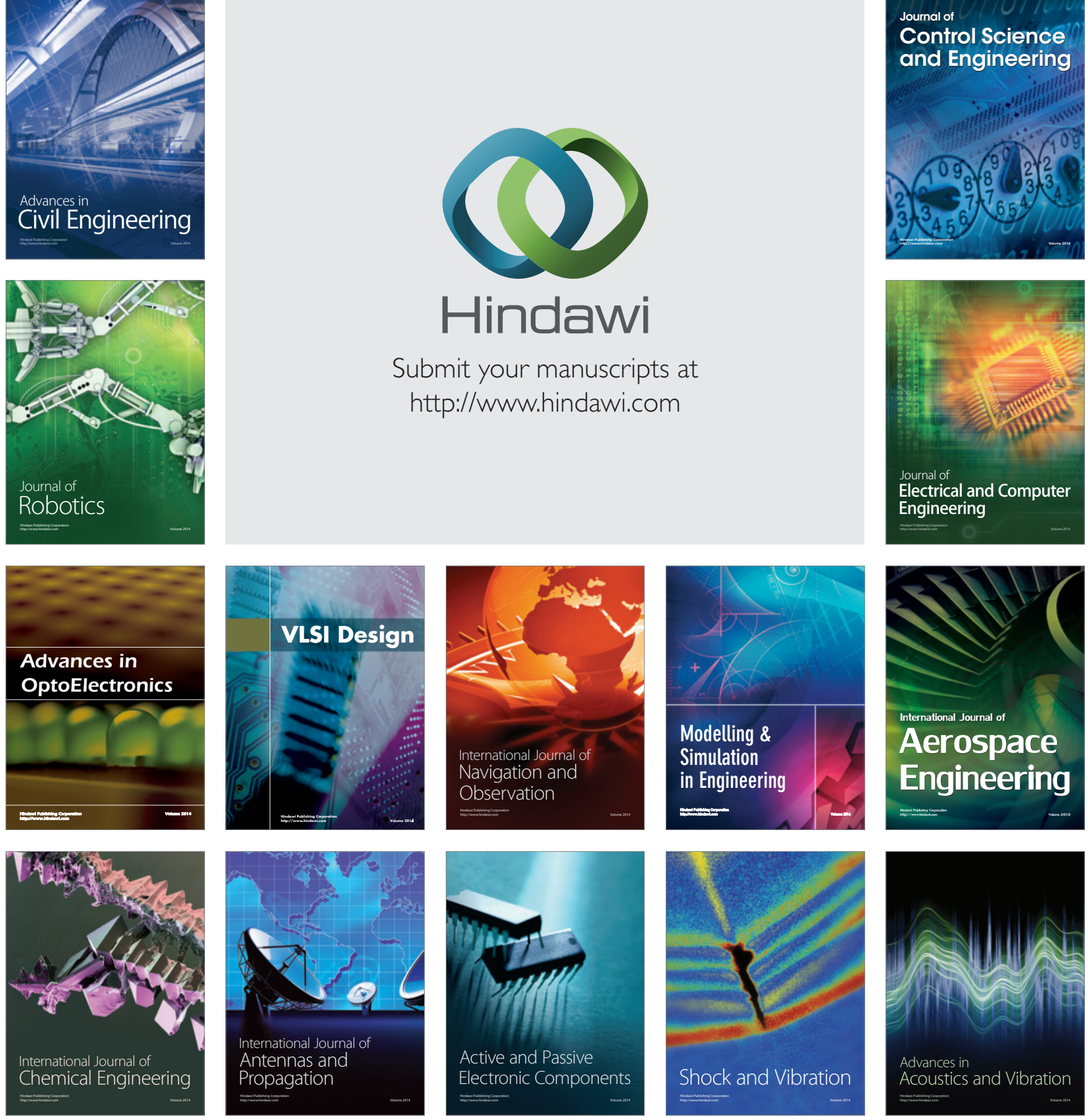